
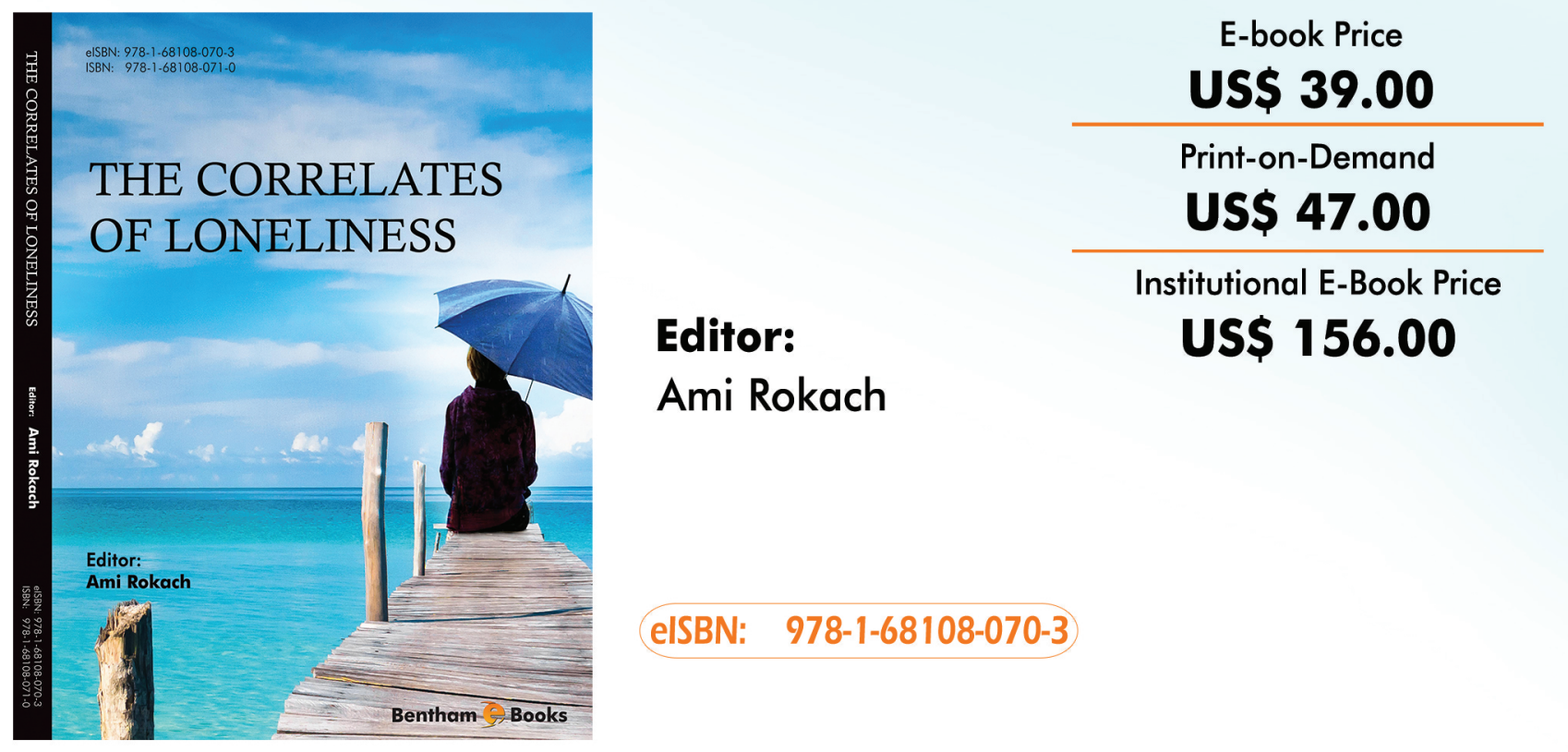

\title{
The correlates of loneliness
}

\section{hith://ehooks.henthamscience.com/hook/9781681080703/}

\section{About the eBook}

The book explains the concept of loneliness in psychological theory and presents a few studies on loneliness among different populations (including a case study on Finnish people).

Written in a clear and systematic manner, The correlates of loneliness is the definitive beginners reference on the topic of loneliness for academicians, sociologists, psychiatrists and general readers.

\section{Contents}

- Modern Loneliness in Historical Perspective

- Loneliness As A Mediator Variable Between Parenting and Coping in Adolescence

- Teachers, Students \& Loneliness in Schools

- Lonely Young People and Technology

- Relationship Between Peer Victimization and Loneliness in Children and Youth: Promising Approaches

- Feeling Inadequate and Alone: The Effects of University Induced Loneliness

- Loneliness, Relationships, and Health

- The Portrayal of Lonely Finnish People

- Loneliness, Coping and Wellbeing Following Marital Loss and Separation: An Empirical Study

For Advertising Inquiries: Contact: marketing@benthamscience.org 